\title{
A COMPARATIVE CROSS-SECTIONAL STUDY ON IMPACT OF SPIRITUALITY AND ITS ASSOCIATED SOCIOECONOMIC FACTORS AMONG ADULTS HEALTH OF 40-60 YEARS AGE IN GWALIOR
}

\author{
Praveen Gautam ${ }^{1}$, Shatkratu Dwivedi2, Swapnil Jain ${ }^{3}$, Piyush Swami ${ }^{4}$
}

${ }^{1}$ Assistant Professor, Department of Community Medicine, G. R Medical College, Gwalior, Madhya Pradesh. 2Postgraduate Resident, Department of Community Medicine, G. R Medical College, Gwalior, Madhya Pradesh. ${ }^{3}$ Medical Officer, District Hospital, Seoni, Madhya Pradesh.

${ }_{4}^{4}$ Postgraduate Resident, Department of Community Medicine, G. R Medical College, Gwalior, Madhya Pradesh.

ABSTRACT

\section{BACKGROUND}

Since the inclusion of spiritual health within WHO's purview, a number of other significant organisations have also attended to spirituality and incorporated reference to it in key documents, including the United Nations action plan Agenda 21 which recognises the right of individuals to "healthy physical, mental, and spiritual development". Studies conducted on common people to analyse the effect of spiritual activities practised by them in their day-to-day life on their health are very few.

The purpose of this study is to assess the relationship of spirituality and health among randomly selected common people of Gwalior region irrespective of their sex, religion, occupation, etc. and to contribute to the vast pool of similar researches conducted worldwide to determine scientific phenomenal value of spirituality.

\section{MATERIALS AND METHODS}

This was a comparative cross-sectional descriptive type study with qualitative components, carried out on individuals in the age group 40-60 years residing in Gwalior region for 1 year (01 Oct '15 to 30 Sep '16). The 200 subjects were divided into two groups of 100 individuals each - one practising any spiritual activity for at least 10 years were grouped into 'Group 1' and others not practising any such activity were grouped into 'Group 2'. Percentages, proportion, graphs, tables, Odds ratio and other statistical methods were used.

\section{RESULTS}

In the study, it was found that Females inculcate spiritual practices in their day-to-day life more in comparison to males. People doing spiritual practice for at least 10 years belong to good or moderate health status \& enjoy other benefits more than those not doing any such practice.

\section{CONCLUSION}

When an individual is tormented with stress, lifestyle syndromes, disorders and diseases; there is a profound need to integrate wholesome preventive, diagnostic and rehabilitative health interventions inclusive of spiritual health. This can be practised by clinics, hospitals, psychotherapeutic centres, embracing good spiritual practices for better health outcome, higher quality of life and reduction of economic burden on governments. These practices, if done with the intension to prevent chronic life style diseases in high risk patients, can give better results than any other medical intervention as "PREVENTION IS BETTER THAN CURE".

\section{KEYWORDS}

Spirituality, Health, Socioeconomic Factors, Adults, Gwalior.

HOW TO CITE THIS ARTICLE: Gautam P, Dwivedi S, Jain S, et al. A comparative cross-sectional study on impact of spirituality and its associated socioeconomic factors among adults health of 40-60 years age in Gwalior. J. Evolution Med. Dent. Sci. 2017;6(4): 308311, DOI: $10.14260 /$ Jemds/2017/69

\section{BACKGROUND}

Spirituality refers to a belief in a higher power, an awareness of life and its meaning, the centring of a person with purpose in life. It involves relationships with a higher being, with self and with the world around the individual. Spirituality implies living with moral standard.[1]

Financial or Other, Competing Interest: None.

Submission 02-12-2016, Peer Review01-01-2017,

Acceptance 06-01-2017, Published 12-01-2017.

Corresponding Author:

Dr. Shatkratu Dwivedi,

Department of Community Medicine,

G. R Medical College,

Gwalior.

E-mail:drshatkratu@gmail.com

DOI: $10.14260 /$ jemds $/ 2017 / 69$
Human Spirituality is increasingly being proven as real scientific phenomenon and not merely a "mental illusion".[2][3] Scientific, Valid and reliable assessment is needed to extend knowledge about WHO's Spiritual dimension of Health \& associated factors. In 1983, 22 WHO member countries from the Eastern Mediterranean Region proposed a draft resolution to this preamble to include reference to spiritual health, such that it would redefine health as a state of "physical, mental, spiritual and social well-being and not merely the absence of disease or infirmity".[4] Whilst WHO did not amend the preamble to its constitution, resolution WHA31.13 passed by the Thirty-seventh World Health Assembly, in 1984.[5] called upon Member States to consider including in their Health For All strategies a spiritual dimension as defined in that resolution in accordance with their own social and cultural patterns ${ }^{[6]}$ recognising that "the spiritual dimension plays a great role in motivating people's achievements in all aspects of life".[7] 
Since the inclusion of spiritual health within WHO's purview, a number of other significant organisations have also attended to spirituality and incorporated reference to it in key documents, including the United Nations action plan Agenda 21[8] which recognises the right of individuals to "healthy physical, mental, and spiritual development". ${ }^{[9]}$

Spirituality is recognised as a factor that contributes to health in many persons. The concept of spirituality is found in all cultures and societies. It is expressed in an individual's search for ultimate meaning through participation in religion and/or belief in God, family, naturalism, rationalism, Yoga, Meditation, humanism and the arts. All these factors can influence how patients and health care professionals perceive health and illness and how they interact with one another.[10] According to an American study on women with various stages of gynaecologic cancers, $76 \%$ indicated that religion had a serious place in their lives, with $49 \%$ becoming more religious since their cancer diagnosis, whereas no one became less religious; $93 \%$ believed that the religious commitment helped to sustain their hopes.[11]

With a large number of researches going on across the world to assess the relation between spirituality and health, an interesting phase of history is expected to come where spirituality may be considered as the 4 th dimension of health along with physical, mental and social dimensions. Religion and spirituality, intertwined with medicine since millennia, became segregated for a few centuries and they are again coming close to embrace each other. Many Indian Beliefs \& practices which were followed from ancient times are being proven scientifically \& not merely blind superstition are becoming accepted in worldwide communities.

Most of the studies being conducted are on either terminally ill patients or healthcare personals. Studies conducted on common people to analyse the effect of spiritual activities practised by them in their day-to-day life on their health are very few. The purpose of this study is to assess the same relationship of spirituality and health among randomly selected common people of Gwalior region irrespective of their sex, religion, occupation, etc. and to contribute to the vast pool of similar researches conducted world-wide to determine scientific phenomenal value of spirituality.

\section{MATERIALS AND METHODS}

The study was mainly dealing with middle aged individuals who tend to inculcate one or other spiritual practices in their daily life and tend to have various health problems. Hence, the study was conducted within the age group of 40-60 years. A cross-sectional descriptive study design was used for the qualitative component of the study. A study proforma was pretested before the actual study was undertaken. The sample for study was selected by random sampling method from the people of Gwalior region. Subjects were selected after obtaining written consent. The study was carried out on individuals in the age group 40-60 years residing in Gwalior region for 1 year (from 01 Oct' 15 to 30 Sep '16).

The subjects were divided into two groups of 100 individuals each - one practising any spiritual activity for at least 10 years were grouped into 'Group 1' and others not practising any such activity were grouped into 'Group 2'. The assessment of practising of spiritual activity was done using pre-tested questionnaire.

Individuals less than 40 years and more than 60 years, nonresponsive and participants who we were unable to contact even after two follow-ups were excluded.

After taking into consideration the exclusion criteria, subjects were asked to give their written consent after informing them the purpose, duration and other relevant details of the study. They were assured that confidentiality will be strictly maintained regarding their personal information. The participants were given the choice to withdraw at any time from the study.

The data was collected from respective subjects through a pre-designed, pre-tested, systematically prepared and validated questionnaire in Hindi. Any queries regarding the proforma were solved accordingly.

After collection, the data was analysed by using various required statistical methods like graphs and tables, percentage, proportions \& Odds-Ratio by using Epi-info statistical software to assess the association of various variables included in the study.

\section{Definitions Used}

In this study, Spirituality is expressed as an individual's search for ultimate meaning through participation in religion and/or belief in God, family, naturalism, rationalism, Yoga, Meditation, humanism and the arts.

Good Health Status- Neither having any chronic illness nor admitted to hospital within last 10 years.

Moderate Health Status- Either having any chronic illness or admitted to hospital within last 10 years.

Poor Health Status- Having any chronic illness and admitted to hospital within last 10 years.

Authors obtained written permissions from the institutional ethics committee.

\section{RESULTS}

The data was analysed and various tables and graphs have been made. Table No. 1 shows Sex-wise distribution of people participated in the study. It shows that females practise spirituality more than males.

\begin{tabular}{|c|c|c|c|c|c|}
\hline & & $\begin{array}{l}\text { Group } 1 \text { (Practising Spirituality) } \\
(n=100)\end{array}$ & $\begin{array}{c}\text { Group } 2 \text { (Not Practising) } \\
(n=100)\end{array}$ & $\begin{array}{l}\text { Odds } \\
\text { Ratio }\end{array}$ & $\begin{array}{c}\mathbf{P} \\
\text { value }\end{array}$ \\
\hline \multirow{2}{*}{ Gender } & Male & $42(42 \%)$ & $62(62 \%)$ & \multirow{2}{*}{0.44} & \multirow{2}{*}{0.004} \\
\hline & Female & $58(58 \%)$ & $38(38 \%)$ & & \\
\hline \multirow{3}{*}{ Education } & Illiterate & $6(6 \%)$ & $2(2 \%)$ & \multicolumn{2}{|c|}{ Reference } \\
\hline & Less than $10^{\text {th }}$ & $20(20 \%)$ & $36(36 \%)$ & 5.4 & 0.03 \\
\hline & $10^{\text {th }}$ and above & $74(74 \%)$ & $62(62 \%)$ & 3.12 & 0.02 \\
\hline
\end{tabular}




\begin{tabular}{|c|c|c|c|c|c|}
\hline \multirow{5}{*}{$\begin{array}{c}\text { Socioeconomic } \\
\text { Status }\end{array}$} & Upper (I) & $16(16 \%)$ & $18(18 \%)$ & \multicolumn{2}{|c|}{ Reference } \\
\hline & Upper middle (II) & $58(58 \%)$ & $34(34 \%)$ & 0.5 & 0.10 \\
\hline & Lower middle (III) & $24(24 \%)$ & $38(38 \%)$ & 0.5 & 0.02 \\
\hline & Upper lower (IV) & $2(2 \%)$ & $10(10 \%)$ & 1.9 & 0.16 \\
\hline & Lower (V) & $0(0 \%)$ & $0(0 \%)$ & NA & NA \\
\hline
\end{tabular}

Among the people doing spiritual practice, $6 \%$ are illiterate, $20 \%$ have had education below 10 th standard and $74 \%$ are educated up to 10 th or more. According to Socioeconomic status (Kuppuswamy scale) of participants in the study, people doing spiritual activity, $16 \%$ are from upper status, 58\% from upper middle, $24 \%$ from lower middle, $2 \%$ from upper lower and none from lower.

Table No. 2 shows health status of participants in the study. Among the people practising spirituality 38\% have good health status, $50 \%$ have moderate and $12 \%$ have poor health status. It shows that people doing any spiritual practice have better health status than those not doing any such activity.

\begin{tabular}{|c|c|c|c|}
\hline $\begin{array}{c}\text { Health } \\
\text { Status }\end{array}$ & $\begin{array}{c}\text { Group 1 (Practising } \\
\text { Spirituality) }\end{array}$ & $\begin{array}{c}\text { Group 2 } \\
\text { (Not Practising) }\end{array}$ & \\
\hline Good & $38(38 \%)$ & $30(30 \%)$ & \multirow{2}{*}{$\mathrm{OR}=1.6$} \\
\hline Moderate & $50(50 \%)$ & $54(54 \%)$ & $\mathrm{P}=0.24$ \\
\hline Poor & $12(12 \%)$ & $16(16 \%)$ & \\
\hline Total & $\mathbf{1 0 0}$ & $\mathbf{1 0 0}$ & \\
\hline \multicolumn{3}{|c|}{ Table 2. Health Status of participants in the Study } \\
\hline
\end{tabular}

Table No. 3 shows Addiction status of participants in the study. People doing spiritual activity have less addiction as compared to people not doing any spiritual activity.

\begin{tabular}{|c|c|c|c|c|}
\hline & Yes & No & Total & \\
\cline { 1 - 4 } $\begin{array}{c}\text { Group 1 } \\
\text { (practising spirituality) }\end{array}$ & $\begin{array}{c}30 \\
(30 \%)\end{array}$ & $\begin{array}{c}70 \\
(70 \%)\end{array}$ & 100 & $\begin{array}{c}\text { OR= } \\
\mathrm{P}=0.76\end{array}$ \\
\cline { 1 - 3 } $\begin{array}{c}\text { Group 2 } \\
\text { (Not practising) }\end{array}$ & $\begin{array}{c}36 \\
(36 \%)\end{array}$ & $\begin{array}{c}64 \\
(64 \%)\end{array}$ & 100 & \\
\cline { 1 - 3 } Total & $\mathbf{6 6}$ & $\mathbf{1 3 4}$ & $\mathbf{2 0 0}$ & \\
\hline \multicolumn{6}{|c|}{ Table 3. Addiction Status of participants in the Study } \\
\hline
\end{tabular}

Table No. 4 shows No. of participants having guilt for addiction. People doing spiritual activity have less guilt as compared to people not doing any spiritual activity.

\begin{tabular}{|c|c|c|c|c|}
\hline & Yes & No & Total & \\
\cline { 1 - 3 } $\begin{array}{c}\text { Group 1 } \\
\text { (practising } \\
\text { spirituality) }\end{array}$ & $\begin{array}{c}8 \\
(26.6 \%)\end{array}$ & $\begin{array}{c}22 \\
(73.3 \%)\end{array}$ & 30 & \multirow{2}{*}{$\mathrm{OR}=0.13$} \\
\cline { 1 - 3 } $\begin{array}{c}\text { Group 2 (Not } \\
\text { practising) }\end{array}$ & $\begin{array}{c}26 \\
(72.2 \%)\end{array}$ & $\begin{array}{c}10 \\
(27.7 \%)\end{array}$ & 36 & \\
\cline { 1 - 3 } Total & $\mathbf{3 4}$ & $\mathbf{3 2}$ & $\mathbf{6 6}$ & \\
\hline \multicolumn{1}{|c|}{ Table 4. No. of Participants having guilt for Addiction } \\
\hline
\end{tabular}

Table No. 5 shows No. of participants who tried to get rid of addictions. People doing spiritual activity tried more to get rid of addictions as compared to people not doing any spiritual activity.

\begin{tabular}{|c|c|c|c|c|}
\hline & Yes & $\begin{array}{l}\text { No } \\
\end{array}$ & Total & \\
\hline $\begin{array}{c}\text { Group 1 } \\
\text { (practising } \\
\text { spirituality) }\end{array}$ & $\begin{array}{c}20 \\
(66.6 \%)\end{array}$ & $\begin{array}{c}10 \\
(33.3 \%)\end{array}$ & 30 & \multirow{2}{*}{$\begin{array}{c}\mathrm{OR}=16 \\
\mathrm{P}=0.001\end{array}$} \\
\hline $\begin{array}{c}\text { Group } 2 \\
\text { (Not practising) }\end{array}$ & $\begin{array}{c}4 \\
(11.1 \%) \\
\end{array}$ & $\begin{array}{c}32 \\
(88.8 \%) \\
\end{array}$ & 36 & \\
\hline Total & 24 & 42 & 66 & \\
\hline
\end{tabular}

Table 5. No. of Participants who tried to get rid of Addiction.

\section{DISCUSSION}

In the study, it was found that Females inculcate spiritual practices in their day-to-day life more in comparison to males. People doing spiritual practice for at least 10 years belong to good or moderate health status group more than those not doing any such practice. Group of people doing spiritual practice were found to have less addictions than those not doing any spiritual practice. Group of people doing spiritual practice were found to experience less guilt for having addictions than those not doing any spiritual practice.

These observations clearly show that people doing any spiritual practice regularly in their day-to-day life for at least 10 years have better health status as they remain happy, calm, contented and satisfied in their lives which directly or indirectly affects their physical health. There are less addictions as they are aware of what is good and what is bad for their health and have ability to control their unnecessary urges. They have satisfaction of what they are doing in their life. Therefore, in spite of having addiction, they do not feel guilt for it in comparison to those not doing any spiritual activity.

Also, according to a cross-sectional study conducted among doctors of North India, $65.65 \%$ had a strong or very strong belief in the spiritual dimension of health; $55.22 \%$ believed in the preventive role of spirituality; $80 \%$ believed in the curative role of spirituality and a similar proportion held the view that spirituality has an important role in dayto-day patient care; and $92.5 \%$ wanted to know more about the scientific work being done in the field of spirituality.[12]

Another similar study conducted among health personnel in the north Indian city of Chandigarh showed that $62 \%$ agreed to the existence of a spiritual dimension to health, $20 \%$ attached primacy to spiritual health, placing it above medical wellness, $59 \%$ of respondents felt that the spiritually healthy coped better with their illness and $86.05 \%$ felt that a spiritual caregiver can provide better patient care; $60.47 \%$ also believed that it was important for caregivers to have spiritual orientations.[13]

This discussion shows that spirituality is a very major factor which directly or indirectly affects our mental health, decisions, thinking and our attitude towards life. All this in turn affects our health as a whole. Thus, spirituality might be considered as a fourth dimension of health in the coming scenario. 


\section{Limitations of the Study}

Spirituality itself is a vast, indistinct \& ill-defined field. Most of the factors and variables used for analysing it vary from person to person.

- Most of the questions asked in the questionnaire were open-ended which caused some problem while analysing and interpreting the data.

- Any practice giving mental peace and satisfaction to one person may not be applicable to another.

- Duration for which a person is doing any spiritual activity cannot be commented as it varies from person to person even for the same activity to attain mental peace.

\section{Recommendations}

The 37th World Health Assembly adopted the historic resolution that the spiritual dimension should be added to the scope of health.[14] During the 58th World Health Assembly at the United Nations in Geneva in May 2005, the growing realisation necessitated a special panel discussion and several reviews on "Spirituality, Religion, and Health".[15]

The last few decades are witnessing resurgence in interest in spirituality in almost all the fields of human endeavour including health. It has now been identified globally as an important aspect for providing answers to many questions related to health and happiness.

India is a country of many religions and sects. Every religion has its own faiths, beliefs and practices which are inculcated in our inner self since childhood. Spiritual practices, if found to prevent diseases, can be a boon for the community as a form of primordial or primary prevention. These practices, if done with the intension to prevent chronic life style diseases in high risk patients, can give better results than any other medical intervention as "prevention is better than cure".

With the present scenario of busy, tense and hectic schedule of most of the people, these practices are being neglected in young age. India being a developing country can decrease its disease burden by promoting awareness about various spiritual practices which a person can easily inculcate in his daily routine at a comparatively younger age to prevent various diseases which they might get later in their life. More studies need to be done on the preventive aspect of spiritual practices.

People who are already suffering from any disease can follow one or the other spiritual practice for early betterment of their health. Health care personals can also use spirituality as an adjuvant to medical treatment for cure or palliation of chronic, life threatening ailments like cancers, AIDS, etc. They should be equipped with the requisite skills to cater to spiritual needs of the patients and should be aware about the need for care of spiritual needs for healing.

Also, further studies and data are needed with larger sample size over longer study period for significant and conclusive results.

\section{CONCLUSION}

Thus, it is vital to include spiritual dimension in the health and prevention of diseases because directly or indirectly spirituality has important role in health care. Introspection and reflection are the invincible cognitive and behavioural tools. Today, public health professionals have hardly any choice but to use these, perhaps much more than ever before. The need of the hour is to think divergently, modify the selftalk, restructure the attitudes and be open. Time has come for a need to discern and manage health beyond the health triangle and be inclusive of the $4^{\text {th }}$ dimension of health, that is, the spiritual dimension.

When an individual is tormented with stress, lifestyle syndromes, disorders and diseases; there is a profound need to integrate wholesome preventive, diagnostic and rehabilitative health interventions inclusive of spiritual health. This can be practised by clinics, hospitals, psychotherapeutic centres, embracing good spiritual practices for better health outcome, higher quality of life and reduction of economic burden on governments.

\section{REFERENCES}

[1] Emery P, Hudson SL. National Center of Continuing Education. Inc. Death and dying: a Christian approach. Available from: https://www.nursece.com/courses/9death-dying-a-christian-approach. Accessed on Aug 20, 2015.

[2] Rose S. Is the term "Spirituality" a word that everyone uses, but nobody knows what anyone means by it? J Contemp Relig 2001;16(2):193-207.

[3] Seaward BL. Health of the human spirit: spiritual dimensions for personal health. USA, Allyn and Bacon: Boston, MA, 2001:p 204.

[4] Review of the constitution of the World Health Organization: report of the executive board special group. 101 st Session. Agenda Item 7.3. Geneva: World Health Organization January 22, 1998.

[5] Thirty-seventh World Health Assembly, Resolution WHA 37.13. Geneva: World Health Organization; 1984. WHO document WHA37/1984/REC/1:6

[6] The fourth ten years of the World Health Organization: 1978-1987. Geneva: World Health Organization, 2011.

[7] Draft Regional Health $\neg$ for $\neg$ all Policy and Strategy for the Twenty-First Century. World Health Organization Regional Office for the Eastern Mediterranean. Fortyfifth Session, Agenda item 15.

[8] Dan S. Agenda 21: The earth summit strategy to save our planet. 1993.

[9] Agenda 21. United Nations Conference on Environment and Development. Chapter 6.23. Rio de Janeiro, 1992.

[10] Association of American Medical Colleges. MSOP Report III. 1999.

[11] Roberts JA, Douglas B, Elkins T, et al. Factors influencing views of patients with gynaecologic cancer about endof-life decisions. Am J Obstet Gynecol 1997;176(1 Pt 1):166-72.

[12] Bansal R, Maroof KA, Parashar P, et al. Spirituality and health: a knowledge, attitude and practice study among doctors of north India. Spirituality and Health International 2008;9(4):263-9.

[13] Goel NK, Walia D, Pathak R, et al. Opinion of health care providers regarding spiritual dimension of health in India. The Internet J of Health 2008;7:1.

[14] Basu S. How the spiritual dimension of health was acknowledged by the World Health Assembly-a report. NAMAH 1995;3:47-51.

[15] Panel discussion on spirituality, religion and health 58TH World Health Assembly, United Nations, Geneva, 2005. 